\title{
Diurnal profiling of neuroendocrine genes in murine heart, and shift in proopiomelanocortin gene expression with pressure-overload cardiac hypertrophy
}

\author{
Jennifer A Chalmers ${ }^{1 *}$, Shuo-Yen J Lin ${ }^{1 *}$, Tami A Martino ${ }^{1,3}$, Sara Arab ${ }^{3}$, Peter Liu ${ }^{1,4}$, \\ Mansoor Husain ${ }^{1,3}$, Michael J Sole ${ }^{1,3}$ and Denise D Belsham ${ }^{1,2,3}$ \\ Departments of ${ }^{1}$ Physiology and ${ }^{2}$ Medicine, and Obstetrics/Gynaecology, University of Toronto, Medical Sciences Building $3247 \mathrm{~A}, 1$ King's College Circle, Toronto, Ontario, \\ M5S 1 A8 Canada \\ ${ }^{3}$ Heart and Stroke/Richard Lewar Centre of Excellence for Cardiovascular Research and Toronto General Hospital Research Institute, Toronto, Canada \\ ${ }^{4}$ Institute of Circulatory and Respiratory Health, Canadian Institutes of Health Research, Ottawa, Canada \\ (Correspondence should be addressed to D D Belsham; Email: d.belsham@utoronto.ca) \\ *J A Chalmers and S-Y J Lin contributed equally to this work
}

\begin{abstract}
Neuroendocrine peptides express biologic activity relevant to the cardiovascular system, including regulating heart rate and blood pressure, though little is known about the mechanisms involved. Here, we investigated neuroendocrine gene expression underlying diurnal physiology of the heart. We first used microarray and RT-PCR analysis and demonstrate the simultaneous expression of neuroendocrine genes in normal murine heart, including POMC, $\mathrm{GnRH}$, neuropeptide $\mathrm{Y}$, leptin receptor, GH-releasing hormone, cocaine- and amphetamine-regulated transcript, proglucagon, and galanin. We examined diurnal gene expression profiles, with cosinar bioinformatics to evaluate statistically significant rhythms. The POMC gene exhibits a day/night, circadian or diurnal, pattern of expression in heart, and we postulated that this may be important to cardiac growth and renewal. POMC diurnal gene rhythmicity is altered in pressure-overload cardiac hypertrophy, when compared with control heart, and levels increased at the dark-to-light transition times. These findings are also consistent with the proposal that neuropeptides mediate adverse remodeling processes, such as occur in pathologic hypertrophy. To investigate cellular responses, we screened three cell lines representing fibroblasts, cardiac myocytes, and vascular smooth muscle cells (NIH3T3, heart line 1, and mouse vascular smooth muscle cell line 1 (Movas-1) respectively). POMC mRNA expression is the most notable in Movas-1 cells and, furthermore, exhibits rhythmicity with culture synchronization. Taken together, these results highlight the diverse neuroendocrine mRNA expression profiles in cardiovasculature, and provide a novel model vascular culture system to research the role these neuropeptides play in organ health, integrity, and disease.
\end{abstract}

Journal of Molecular Endocrinology (2008) 41, 117-124

\section{Introduction}

The heart as an endocrine organ produces the hormone proopiomelanocortin (POMC; Forman \& Bagasra 1992). POMC production is of particular interest, because it encodes many biologically active peptides relevant to cardiovascular physiology, such as adrenocorticotropic hormone, $\beta$-endorphin, and $\alpha$ - and $\gamma$-melanocyte-stimulating hormones (MSHs) (Diz \& Jacobowitz 1983, Saito et al. 1983, Ekman et al. 1989, Millington et al. 1993, 1999, Ni et al. 2003). However, little is known about POMC gene expression in the heart and mechanisms of regulation in health and disease.

Previous studies demonstrate that $>10 \%$ of cardiac genes exhibit diurnal expression patterns underlying homeostasis and pathophysiology (Young et al. 2001b, Storch et al. 2002, Martino et al. 2004, 2007a). Rhythmic gene expression in the heart is believed to underlie key physiologic functions, including heart rate, blood pressure, myocardial contractile performance, carbohydrate oxidation, oxygen consumption (Muller et al. 1985, Young et al. 2001a), and contribute to the timing of the onset of acute cardiac events (e.g., myocardial infarction, sudden cardiac death; Muller et al. 1985, Haus et al. 1989, Brzezinski 1997, Charloux et al. 1999). In this study, we focused on POMC gene expression in normal murine heart and pressure-overload cardiac hypertrophy. In addition, we extended investigations toward additional neuroendocrine genes expressed in the vascular-derived mouse vascular smooth muscle cell line 1 (Movas-1) cells. We find that POMC, in particular, exhibited rhythmic gene cycling similar to what is observed in the heart. Overall, these studies provide a new insight into the endocrinology relevant to cardiovascular function, and further provide a novel cell 
model for examining the regulation of these peptides. Ultimately, these findings may translate to the clinical setting, providing evidence for the importance of the maintenance of normal circadian rhythms, critical for heart health (Martino et al. 2008).

\section{Materials and methods}

\section{Animals}

All animal protocols were reviewed and approved by the University of Toronto Institutional Animal Care and Use Committee. Six-week-old male $\mathrm{C} 57 \mathrm{Bl} / 6$ mice were entrained to a normal $12 \mathrm{~h}$ light:12 h darkness cycle (LD 12:12) for 2 weeks time. They were then subjected to surgery or sham and maintained under the normal LD 12:12 cycle for a further 4 weeks. Animals were killed by decapitation and heart tissue was collected across the 24-h diurnal cycles, as described (Martino et al. 2007a). In a separate experiment to investigate gene expression in heart disease, pressure-overload cardiac hypertrophy was induced using a well-documented model of transthoracic aortic constriction (TAC) and compared with control (sham). Hearts from TAC and shamoperated mice were collected across the diurnal cycle, as described previously. A total of three samples were collected at each time point, at 4-h intervals over $24 \mathrm{~h}$, from TAC and sham mice, and frozen at $-80^{\circ} \mathrm{C}$ until used.

\section{Microarrays}

Microarrays were used for global gene expression analysis, and we focused on the expression of neuroendocrine genes in the heart. We used the Affymetrix murine GeneChips (M0E430A). Briefly, RNA was purified from heart tissue by TRIzol reagent (Invitrogen). Integrity and highest quality were validated by ethidium bromide agarose gel electrophoresis, and BioAgilent spectrophotometry. First-strand cDNA synthesis, labeling, and hybridization to the microarray gene chips were performed using automated Affymetrix protocols. Scanning and per-chip normalizations were performed using MicroArray Suite version 5 (MASv5) and manufacturer specifications. GeneSpring (Agilent, Santa Clara, CA, USA) was used for visualizing gene expression patterns, and also for hierarchical cluster analyses, correlations, and ontology. Twenty-four hours of rhythmic gene profiles were determined by COSOPT analysis, a well-documented biocomputational program that interrogates daily gene cycling in microarray data (Panda et al. 2002, Martino et al. 2004). COSOPT provides an integer termed parameter multiple measures corrected- $\beta$ (pMMC- $\beta$ ), which denotes the statistical significance of rhythms identified.

\section{Movas-1}

Movas-1 cells were grown in Dulbecco's modified Eagle medium (DMEM; Sigma-Aldrich) supplemented with both $10 \%$ fetal bovine serum (FBS; Hyclone; distributed by Fisher Scientific, Ottawa, Canada), and 1\% penicillin-streptomycin by volume (Gibco, distributed by Invitrogen) (Afroze et al. 2003). The cells were maintained in a tissue culture incubator at $37^{\circ} \mathrm{C}, 5 \%$ $\mathrm{CO}_{2}$. NIH3T3 cells were grown in DMEM with $10 \% \mathrm{FBS}$, and $1 \%$ pen-strep as described previously. The heart line 1 (HL-1) cell line was grown in Claycomb Media, $10 \%$ FBS (by volume), with $100 \mu \mathrm{g} / \mathrm{ml}$ pen-strep, $0 \cdot 1 \mathrm{mM}$ norepinephrine, and $2 \mathrm{mM}$ L-glutamine, according to the protocol previously described (Claycomb et al. 1998).

\section{Analysis of POMC gene expression in Movas- 1 cells}

Movas-1 cells were plated to confluence in $60 \mathrm{~mm}^{2}$ tissue culture dishes and grown to confluency overnight (12-16 h; Falcon, distributed by VWR, Mississauga, Canada). For control or baseline values, the cells were scraped from the plates using a plastic scraping tool, every $4 \mathrm{~h}$ for $24 \mathrm{~h}$. RNA was isolated using the guanidium thiocyanate-phenol-chloroform extraction method (Chomczynski \& Sacchi 1987), and quantified via spectrophotometry to determine concentration and demonstrate high-quality purification. For experiments examining gene rhythmicity in vitro, confluent cells were first starved in serum-free media (supplemented with $5 \%$ pen-strep) for $12 \mathrm{~h}$. The cells were then serum shocked with $20 \%$ FBS for $30 \mathrm{~min}$. Serum shock is currently the standard method used to synchronize cells in culture (Hurst et al. 2002, Young 2006). Following serum shock, the cells were returned to normal culture conditions and samples were collected every $4 \mathrm{~h}$ for $36 \mathrm{~h}$. Expression was determined by RT-PCR, as opposed to microarray.

\section{Semi-quantitative reverse transcription (RT)-PCR}

Gene expression patterns in the microarray data, and the Movas-1 cells, were both further confirmed by RT-PCR using the One-Step RT-PCR kit (Qiagen) according to the manufacturer instructions (see Table 1 for primer sequences). All PCR-amplified products were visualized on $2 \%$ agarose gels containing ethidium bromide, under u.v. light. Relative gene expression levels were quantified by densitometry on a Kodak Image Station 2000R. Expression values were normalized to histone. The PCR amplicons were verified by purification (Qiagen MinElute PCR Purification Kit) and sequencing (The Centre for Applied Genomics, the Hospital for Sick Children, MaRS Centre, Toronto, Ontario, Canada). Results were 
Table 1 Primer sequences used to screen for neuropeptides

Primer sequences for neuropeptides

\begin{tabular}{|c|c|c|c|c|c|}
\hline \multicolumn{6}{|c|}{ Primer sequences for neurop } \\
\hline & \multirow[b]{2}{*}{ PCR template } & \multicolumn{2}{|l|}{ Cycle number } & \multirow[b]{2}{*}{ Annealing temp } & \multirow[b]{2}{*}{ Product size (bp) } \\
\hline & & Heart Tissue & Movas-1 & & \\
\hline \multicolumn{6}{|l|}{ Gene } \\
\hline $\mathrm{GnRH}$ & $\begin{array}{l}\text { S: actgtgtgtttggaaggctgc } \\
\text { A: ttccagagctcctcgcagatc }\end{array}$ & 40 & 40 & 62 & 162 \\
\hline $\mathrm{GHRH}$ & $\begin{array}{l}\text { S: ttgtgatcctcatcctcaccag } \\
\text { A: atcactttccgggcatacag }\end{array}$ & 40 & 40 & 60 & 128 \\
\hline ProGlu & $\begin{array}{l}\text { S: ttcaccagcgactacagcaaa } \\
\text { AS: ggtttgaatcagccagttgat }\end{array}$ & 40 & 40 & 60 & 351 \\
\hline NPY & $\begin{array}{l}\text { S: taggtaacaagcgaatgggg } \\
\text { AS: acatggaagggtcttcaagc }\end{array}$ & 40 & 40 & 60 & 282 \\
\hline POMC 1 & $\begin{array}{l}\text { S: tagatgtgtggagctggtgc } \\
\text { AS: cagtcaggggctgttcatct }\end{array}$ & 40 & $\mathrm{n} / \mathrm{a}$ & 60 & 149 \\
\hline POMC 2 & $\begin{array}{l}\text { S: atgccgagattctgctacagtcg } \\
\text { AS: ttcatctccgttgccaggaaaca }\end{array}$ & $\mathrm{n} / \mathrm{a}$ & 45 & 60 & 191 \\
\hline CART & $\begin{array}{l}\text { S: agctcccgcctgcggctgct } \\
\text { AS: cagtcacacagcttcccgatcc }\end{array}$ & 40 & 40 & 60 & 299 \\
\hline Galanin & $\begin{array}{l}\text { S: catgccattgacaaccacag } \\
\text { AS: ggattggcttgaggagttgg }\end{array}$ & 34 & 40 & 55 & 320 \\
\hline $\mathrm{ObRb}$ & $\begin{array}{l}\text { S: atgacgcagtgtactgctg } \\
\text { AS: gtggcgagtcaagtgaacct }\end{array}$ & 28 & 40 & 60 & 356 \\
\hline Histone & $\begin{array}{l}\text { S: gcaagagtgcgccctctactg } \\
\text { AS: ggcctcacttgcctcgtgcaa }\end{array}$ & 21 & 25 & 60 & 217 \\
\hline
\end{tabular}

$\mathrm{S}$, sense; AS, antisense.

compared for sequence homology by BLAST analysis on the NCBI website. Specific changes in gene expression patterns between test groups were evaluated statistically by ANOVA, followed by Bonferroni's multiple comparison test (Prism 4.0). Statistical significance was determined at $P<0.05$.

\section{Results}

\section{Neuroendocrine genes in the heart}

We first investigated expression of neuroendocrine genes in the normal murine heart. We detected expression of POMC, gonadotropin-releasing hormone (GnRH), neuropeptide Y (NPY), leptin receptor $(\mathrm{ObRb})$, growth hormone-releasing hormone (GHRH), cocaine- and amphetamine-regulated transcript (CART), proglucagon (ProGlu), and galanin genes in the heart by microarray analysis, and subsequently verified these results using RT-PCR. Hypothalamic RNA was used as a control (Fig. 1).

\section{POMC gene expression in heart is circadian}

We examined the neuroendocrine genes for cosinar rhythms using COSOPT analysis, a well-documented biocomputational program that interrogates daily gene cycling in microarray data (Panda et al. 2002, Martino et al. 2004), in normal (sham-perated) mouse hearts. The $P O M C$ gene profile exhibited a robust rhythm over 24-h diurnal cycles, both by microarray analyses (Fig. 2A) and by semi-quantitative RT-PCR (Fig. 2B and C). The POMC gene expression peaked at night, $\sim 4 \mathrm{~h}$ after lights off $(\mathrm{ZT}=16)$, during the activity phase for mice (mice are active in the dark or nocturnal). The trough of $P O M C$ expression occurs during the day, $\sim 4-7 \mathrm{~h}$ following lights on (ZT 4-7; subjective night or sleep).

\section{Aortic constriction alters POMC gene expression profile}

We next examined POMC gene expression in heart disease. We performed a parallel microarray study, but used mice subject to aortic constriction-induced cardiac hypertrophy versus sham-operated controls. As shown in Fig. 3, the sham mice exhibited the same expression profile as our control mice from the first experiment above, thus validating the methods used. Remarkably, POMC gene expression in TAC mice phase shifted relative to the sham control mice. That is, in contrast to normal heart, the peak for cardiac POMC expression in hypertrophied heart occurred $\sim 8 \mathrm{~h}$ after lights off $(\mathrm{ZT}=20)$. Additionally, significant differences were observed in the overall levels of POMC mRNA expression in cardiac hypertrophy, at ZT 3 and ZT 22 $(* P<0 \cdot 05$; Fig. 3). 


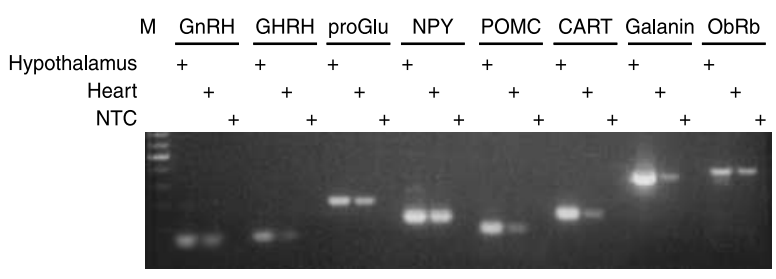

Figure 1 One-step RT-PCR screening results for neuropeptides in heart samples. Heart samples were positive for all neuropeptides tested. GnRH, gonadotropin-releasing hormone; GHRH, growth hormone-releasing hormone; NPY, neuropeptide Y; POMC, proopiomelanocortin; CART, cocaine- and amphetamineregulated transcript; ObRb, leptin receptor. Mouse hypothalamus was used as a positive control. M indicates molecular weight markers, NTC (no template control).

\section{Expression of neuroendocrine genes in Movas- 1 cells}

We studied a pure heart-derived cell culture system, which can be used to examine diurnal neuroendocrine gene expression in vitro. These cell lines do not have any sympathetic neuronal cell types that may be present when isolating the entire heart for analysis. We screened three cell lines representative of cardiac-derived cells: immortalized murine vascular smooth muscle cells (Movas-1), murine fibroblasts (NIH3T3), and cardiomyocytes (HL-1). We determined that only Movas-1 cells, similar to the cardiovasculature, express mRNA for $P O M C$, galanin, $O b R b$, tryptophan hydroxylase $(T P H)$, ProGlu, and GnRH (Table 2). It should be noted that the primer set used to amplify the POMC mRNA in the Movas-1 cells detects the full-length POMC mRNA and not the truncated form (Millington et al. 1999). This fulllength POMC mRNA includes a region coding for a signal peptide that ensures translation of the transcript into protein. We then examined temporal gene expression of POMC in the Movas-1 cells. The cells were synchronized by serum shock, consistent with methods for inducing circadian gene cycling in vitro (Kaeffer \& Pardini 2005). Movas-1 cells with serum shock showed a distinct pattern in POMC expression, and this differed significantly from untreated controls at the 12and 36-h time points $(P<0.001$ and $P<0.05$ respectively). When Movas-1 cells were treated with a $20 \%$ serum shock, $P O M C$ mRNA exhibits a predictable pattern over time. This pattern in $P O M C$ mRNA was nearly identical
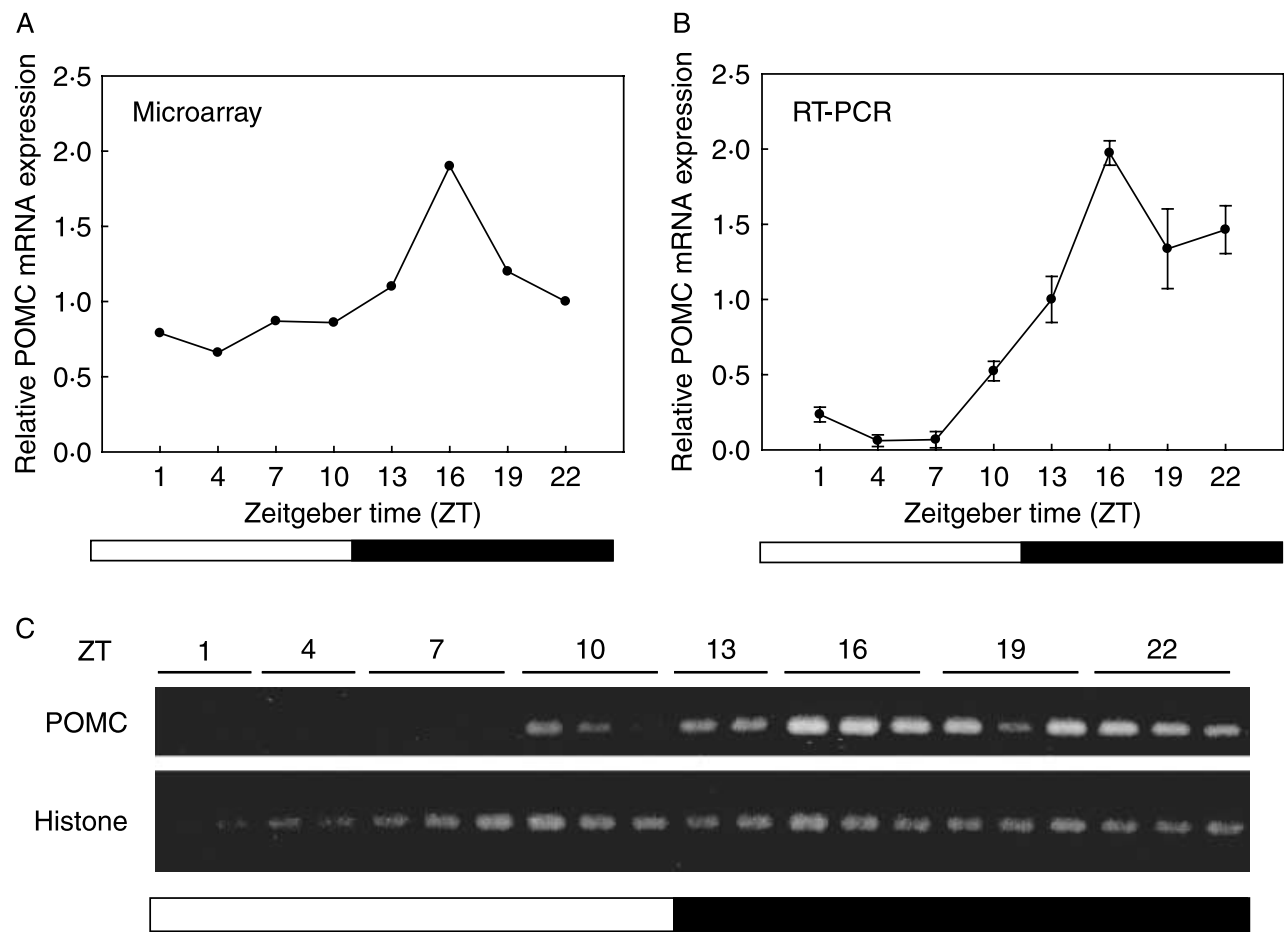

Figure 2 (A) Microarray data showing significant variation in relative POMC mRNA expression over time in the normal murine heart. (B) One-step semi-quantitative RT-PCR conducted on heart tissue to confirm results from the microarray data, $n=3$ for each time point, for both banded and sham animals.

(C) Representative gel of data shown in $\mathrm{B}$, illustrating the change in relative POMC mRNA expression compared with histone gene expression control over time. Animals were placed on a $12 \mathrm{~h}$ light:12 $\mathrm{h}$ darkness cycle (LD) schedule. Zeitgeber time corresponds to the time of day at which the tissue was harvested. Bar underneath graph indicates lights on in white and when lights were off in black. 


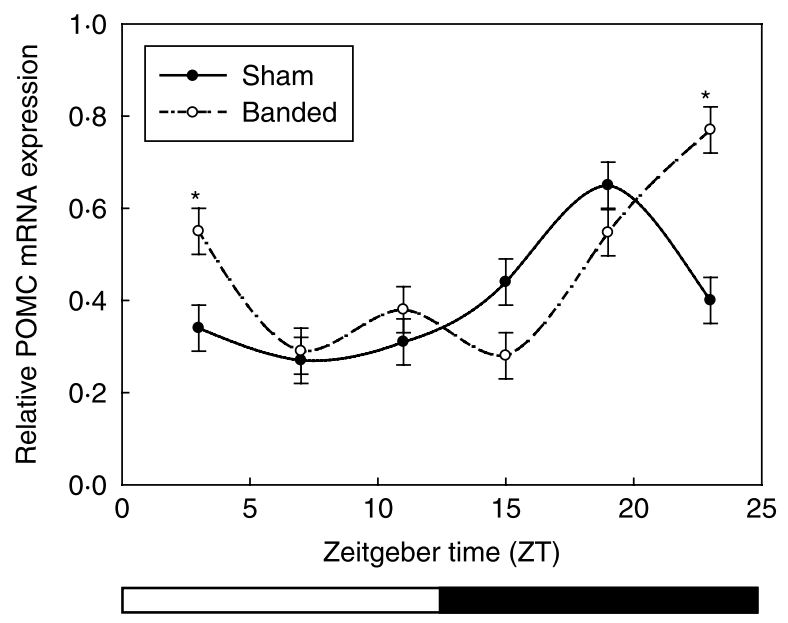

Figure 3 Microarray data displaying relative POMC mRNA expression over time from the heart tissue of mice that underwent TAC (Trans-aortic constriction) surgery versus sham animals over time. $n=3$ for each time point, for both banded and sham animals. POMC mRNA expression was significantly different in sham versus banded animals at points indicated $\left({ }^{\star} P<0 \cdot 05\right)$. The animals undergoing TAC showed a phase shift in peak $P O M C$ mRNA expression of $4 \mathrm{~h}$.

to the rhythmic expression of the circadian clock gene brain and muscle aryl hydrocarbon receptor nuclear translocator (ARNT) like (BMAL1) that we have observed post-serum shock in the Movas-1 cells (JA Chalmers, TA Martino, N Tata, MR Ralph, MJ Sole \& DD Belsham, unpublished observations), which suggests that they may be similarly regulated by the circadian clock. These results demonstrate synchronization of Movas-1 cells. Furthermore, cell culture synchrony by serum shock resulted in robust gene expression cycling in POMC mRNA, when compared with control.

Table 2 Results of one-step RT-PCR screening in mouse vascular smooth muscle cell line 1 (Movas-1) cell line for neuropeptides found to be present in the heart tissue

\section{Neuropeptides in Movas- 1 cells}

\section{Peptide}

Cocaine- and amphetamine-regulated transcript (CART)

Galanin

Growth hormone-releasing hormone

(GHRH)

Leptin receptor $(\mathrm{ObRb})$

Tryptophan hydroxylase (TPH)

Proglucagon (proGlu)

Proopiomelanocortin (POMC)

Gonadotropin-releasing hormone

(GnRH)

Neuropeptide Y (NPY)

+ , detectable; - , absent.
As culture synchronization is deemed important for coordinating cell cycle and/or circadian processes, this provides a potential new mechanism for understanding neuroendocrine gene expression and regulation in peripheral tissues in vivo.

\section{Discussion}

In this study, we describe a group of neuroendocrine genes expressed in murine heart, based on microarray and RT-PCR data. These included GHRH, CART, ProGlu, and galanin, which have never before been investigated in heart tissue, along with GnRH, NPY, POMC, and the long active form of $\mathrm{ObRb} \mathrm{mRNA}$. These findings add significantly to a growing list of neuroendocrine genes and products relevant to the cardiovascular system. We next examined the diurnal expression pattern of these genes in hearts from both control and TAC mice. We found that in the heart, the only gene with a distinct and significant diurnal rhythm was POMC (Supplemental Fig. 1, which can be viewed online at http://jme.endocrinology-journals.org/ content/vol41/issue/). Therefore, we focused on this gene for the remainder of our study.

The $P O M C$ gene produces peptides previously localized to cardiocytes by immunohistochemical analyses (Diz \& Jacobowitz 1983, Saito et al. 1983, Ekman et al. 1989, Millington et al. 1993, 1999, Ni et al. 2003). Here, we confirmed these findings and demonstrated that not only is it encoded by cardiac cells with a panel of other neuroendocrine genes, but also the $P O M C$ gene expression exhibited a rhythmic profile consistent with the 24-h period. We postulated that as such, $P O M C$ gene expression underlies physiology relevant to the cardiovascular system.

We next investigated $P O M C$ expression in vitro and provided evidence for a new model system for investigating relevant cell mechanisms. To do this, we screened several cell lines that represent different cell types found collectively in the heart. We examined the Movas-1 (vascular smooth muscle) cell line, the NIH3T3 (fibroblast) line, and the HL-1 (cardiomyocyte) line. Movas-1 was the only cell type to express $P O M C$ mRNA and, in addition, the cells were also positive for agouti-related peptide (AgRP), galanin, ObRb, TPH, proGlu, and GnRH. Furthermore, we demonstrated using serumshock synchronization that $P O M C$ gene expression was rhythmic in Movas-1 cells. It is particularly interesting to observe rhythmicity in this key neuroendocrine gene outside of the brain. The profile of POMC expression in these cells closely mimics the pattern of BMAL1 (JA Chalmers, TA Martino, N Tata, MR Ralph, MJ Sole \& DD Belsham, Unpublished observations). As BMAL1 gene expression in the brain and other tissues is regulated by several other circadian transcription factors, further work is required to first determine whether the clock 
directly controls $P O M C$ expression and, if so, which of these regulators is responsible (Reppert \& Weaver 2001, 2002). The existence of E-box-binding sites in the promoter region of the POMC gene (Fig. 4) lends further support to the hypothesis of transcriptional regulatory control similar to that found in the brain and points to avenues of future direction (O'Donohue et al. 1979a,b, Monnet et al. 1981, Scimonelli et al. 1987).

Peripheral tissues, such as the heart, and also cell lines representative of non-neuronal tissues, express a remarkable collection of neuroendocrine genes. The regulation of these genes is likely important in organ structure and function, and further analysis of their role in cardiovascular endocrinology is warranted. For example, the peptide product $\gamma$-MSH, a natriuretic peptide derived from $P O M C$, is actively investigated for its role in regulating a variety of cardiovascular functions, most notably affects on heart rate and blood pressure. This peptide is commonly thought to exert its cardiovascular action via the melanocortin 3 receptor, which binds with high selectivity and affinity in the anteroventral third ventricle region of the brain. We speculate that diurnal profiles of $P O M C$ mRNA synthesis, and peptide

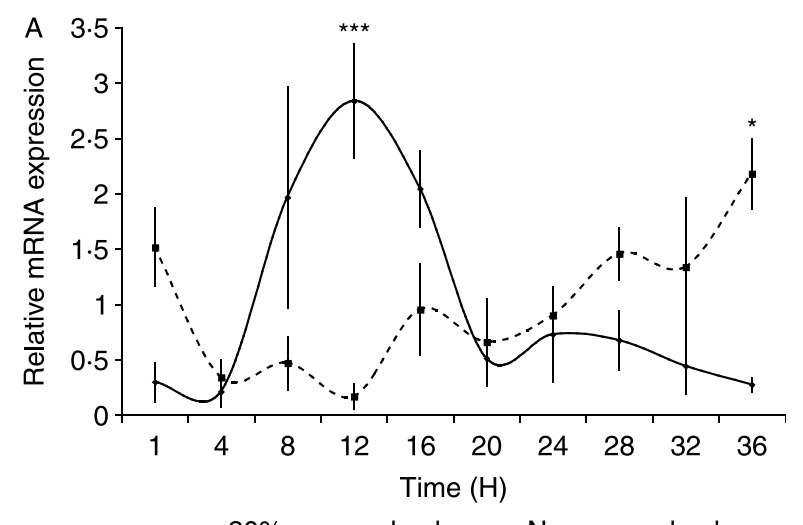

$\rightarrow 20 \%$ serum shock - No serum shock

B

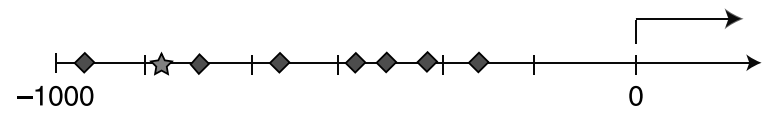

E-box on forward strand

E-box on reverse strand

Figure 4 (A) Relative POMC mRNA expression in Movas-1 cells given no serum shock (dashed line) compared with cells given a $20 \%$ FBS serum shock (solid line) over time. Movas- 1 cells displayed a distinct pattern over time after treatment with a serum shock, $n=3$ with no serum shock, $n=4$ with serum shock. Asterisks indicate differences between POMC mRNA expression with and without serum shock, ${ }^{\star} P<0.05,{ }^{\star \star \star} P<0.001$.

(B) Schematic of $P O M C$ promoter indicating the location of E-boxes where core clock transcription factors may potentially bind. production, can facilitate the heart rate and blood pressure increase that occurs normally in the subjective day or active period, and the decrease at night or sleep period. Further support for this notion of diurnal availability of $P O M C$ for cardiovascular processes comes from findings that $\gamma$-MSH administered in the central nervous system (CNS) stimulates sympathetic outflow, increases mean arterial pressure, and produces tachycardia in most (Gruber \& Callahan 1989, Wikberg et al. 2000, Schioth 2001), but not all (De Wildt et al. 1993, 1994) reports. Moreover, Ni et al. (2003) present evidence of a hypotensive role for $\gamma$-MSH in salt-sensitive hypertensive mice further supporting our hypothesis.

We observed a shift in the POMC diurnal gene expression profile in pressure-overload murine heart. The mechanism by which this occurs is not clear. One possibility is the underlying cell circadian mechanism. However, our previous studies demonstrated that the core clock genes (per2, bmal, rev-erb, etc.) and overall phase of rhythmicity in TAC heart do not change when compared with sham (Young et al. 2001b, Martino et al. 2007a). A more likely possibility is derived from the significant increase in blood pressure; this may contribute to the altered $P O M C$ expression profile in much the same manner as the matrix remodeling genes, which also change expression profiles in hypertrophic heart versus sham. Also, there is small vessel hyperplasia in heart along with perivascular fibrosis, a compensatory response to the high-pressure environment due to the aortic ligature. This observation of vasculopathy, in combination with the rhythmic expression of $P O M C$ gene expression in vascular myocytes (Movas-1) in vitro, provides a basis for the changes that occur. Lastly, there are very recent investigations by our group and others examining the diurnal proteome in peripheral organs (Reddy et al. 2006, Martino et al. 2007b). An interesting future experiment would be to determine which $P O M C$-derived products are produced at differing times in the heart, and how this changes in heart disease. Use of in vivo Langendorff could further provide information on the effects that occur in the day versus night, as well as responses to inhibitors given at specific times across the diurnal cycle.

In summary, we show expression of important neuroendocrine genes in the mammalian heart. Many of their gene products are involved in regulatory processes vital for cardiovascular physiology. In neural tissues, their timing of expression is presumed to underlie physiology, and thus we hypothesize a similar temporal role in peripheral tissues, such as the heart. We detect diurnal profiles of neuroendocrine genes expressed in normal heart. That diurnal profiles are also observed in heart disease, and specifically that $P O M C$ expression changes with the development of pathologic hypertrophy provides intriguing evidence for a potential role of circadian dysregulation in disease. We also investigated the non-neural cellular 
regulation of these genes, and demonstrated clear and reproducible expression in vascular myocytes in vitro. Culture synchronization by serum shock established a rhythmic gene phenotype in vitro and is consistent with neuroendocrine rhythms in the murine heart in vivo. These studies may shed new light and understanding on gene expression patterns underlying cardiovascular physiology and pathology and present novel avenues for future research in heart disease.

\section{Declaration of interest}

The authors declare that there is no conflict of interest that could be perceived as prejudicing the impartiality of the research reported.

\section{Funding}

This work was supported by the Heart and Stroke Foundation of Ontario (HSFO). D D B holds a Canada Research Chair in Neuroendocrinology and is a Canada Foundation for Innovation Researcher. J A C was funded by the National Sciences of Engineering Council.

\section{Acknowledgements}

T A M acknowledges the HSFO, and the HSRLCECR.

\section{References}

Afroze T, Yang LL, Wang C, Gros R, Kalair W, Hoque AN, Mungrue IN, Zhu Z \& Husain M 2003 Calcineurin-independent regulation of plasma membrane $\mathrm{Ca}^{2+}$ ATPase- 4 in the vascular smooth muscle cell cycle. American Journal of Physiology. Cell Physiology 285 C88-C95.

Brzezinski A 1997 Melatonin in humans. New England Journal of Medicine 336 186-195.

Charloux A, Gronfier C, Lonsdorfer-Wolf E, Piquard F \& Brandenberger G 1999 Aldosterone release during the sleep-wake cycle in humans. American Journal of Physiology 276 E43-E49.

Chomczynski P \& Sacchi N 1987 Single-step method of RNA isolation by acid guanidinium thiocyanate-phenol-chloroform extraction. Analytical Biochemistry 162 156-159.

Claycomb WC, Lanson NA Jr, Stallworth BS, Egeland DB, Delcarpio JB, Bahinski A \& Izzo NJ Jr 1998 HL-1 cells: a cardiac muscle cell line that contracts and retains phenotypic characteristics of the adult cardiomyocyte. PNAS 95 2979-2984.

Diz DI \& Jacobowitz DM 1983 Cardiovascular effects of intrahypothalamic injections of alpha-melanocyte stimulating hormone. Brain Research 270 265-272.

Ekman R, Bjartell A, Lisander B \& Edvinsson L 1989 Gamma 2-MSH immunoreactivity in the human heart. Life Sciences 45 787-792.

Forman LJ \& Bagasra O 1992 Demonstration by in situ hybridization of the proopiomelanocortin gene in the rat heart. Brain Research Bulletin 28 441-445.

Gruber KA \& Callahan MF 1989 ACTH-(4-10) through gamma-MSH: evidence for a new class of central autonomic nervous systemregulating peptides. American Journal of Physiology 257 R681-R694.

Haus E, Nicolau G, Lakatua DJ, Sackett-Lundeen L \& Petrescu E 1989 Circadian rhythm parameters of endocrine functions in elderly subjects during the seventh to the ninth decade of life.

Chronobiologia 16 331-352.
Hurst WJ, Mitchell JW \& Gillette MU 2002 Synchronization and phaseresetting by glutamate of an immortalized SCN cell line. Biochemical and Biophysical Research Communications 298 133-143.

Kaeffer B \& Pardini L 2005 Clock genes of mammalian cells: practical implications in tissue culture. In Vitro Cellular and Developmental Biology. Animal 41 311-320.

Martino T, Arab S, Straume M, Belsham DD, Tata N, Cai F, Liu P, Trivieri M, Ralph M \& Sole MJ 2004 Day/night rhythms in gene expression of the normal murine heart. Journal of Molecular Medicine 82 256-264.

Martino TA, Tata N, Belsham DD, Chalmers J, Straume M, Lee P, Pribiag H, Khaper N, Liu PP, Dawood F et al. 2007 a Disturbed diurnal rhythm alters gene expression and exacerbates cardiovascular disease with rescue by resynchronization. Hypertension 49 1104-1113.

Martino TA, Tata N, Bjarnason GA, Straume M \& Sole MJ 2007b Diurnal protein expression in blood revealed by high throughput mass spectrometry proteomics and implications for translational medicine and body time of day. American Journal of Physiology. Regulatory, Integrative and Comparative Physiology 293 R1430-R1437.

Martino TA, Oudit GY, Herzenberg AM, Tata N, Koletar MM, Kabir GM, Belsham DD, Backx PH, Ralph MR \& Sole MJ 2008 Circadian rhythm disorganization produces profound cardiovascular and renal disease in hamsters. American Journal of Physiology. Regulatory, Integrative and Comparative Physiology 294 R1675-R1683.

Millington WR, Evans VR, Forman LJ \& Battie CN 1993 Characterization of beta-endorphin- and alpha-MSH-related peptides in rat heart. Peptides 14 1141-1147.

Millington WR, Rosenthal DW, Unal CB \& Nyquist-Battie C 1999 Localization of pro-opiomelanocortin mRNA transcripts and peptide immunoreactivity in rat heart. Cardiovascular Research 43 $107-116$.

Monnet F, Reubi JC, Eberle A \& Lichtensteiger W 1981 Diurnal variation in the release of alpha-MSH from rat hypothalamus and pituitary. Neuroendocrinology 33 284-287.

Muller JE, Stone PH, Turi ZG, Rutherford JD, Czeisler CA, Parker C, Poole WK, Passamani E, Roberts R, Robertson T et al. 1985 Circadian variation in the frequency of onset of acute myocardial infarction. New England Journal of Medicine 313 1315-1322.

Ni XP, Pearce D, Butler AA, Cone RD \& Humphreys MH 2003 Genetic disruption of gamma-melanocyte-stimulating hormone signaling leads to salt-sensitive hypertension in the mouse. Journal of Clinical Investigation 111 1251-1258.

O’Donohue TL, Miller RL \& Jacobowitz DM 1979 $a$ Identification, characterization and stereotaxic mapping of intraneuronal alphamelanocyte stimulating hormone-like immunoreactive peptides in discrete regions of the rat brain. Brain Research 176 101-123.

O'Donohue TL, Miller RL, Pendleton RC \& Jacobowitz DM $1979 b$ A diurnal rhythm of immunoreactive alpha-melanocyte-stimulating hormone in discrete regions of the rat brain. Neuroendocrinology $\mathbf{2 9}$ 281-287.

Panda S, Antoch MP, Miller BH, Su AI, Schook AB, Straume M, Schultz PG, Kay SA, Takahashi JS \& Hogenesch JB 2002 Coordinated transcription of key pathways in the mouse by the circadian clock. Cell 109 307-320.

Reddy AB, Karp NA, Maywood ES, Sage EA, Deery M, O'Neill JS, Wong GK, Chesham J, Odell M, Lilley KS et al. 2006 Circadian orchestration of the hepatic proteome. Current Biology 16 $1107-1115$.

Reppert SM \& Weaver DR 2001 Molecular analysis of mammalian circadian rhythms. Annual Review of Physiology 63 647-676.

Reppert SM \& Weaver DR 2002 Coordination of circadian timing in mammals. Nature 418 935-941.

Saito E, Iwasa S \& Odell WD 1983 Widespread presence of large molecular weight adrenocorticotropin-like substances in normal rat extrapituitary tissues. Endocrinology 113 1010-1019. 
Schioth HB 2001 The physiological role of melanocortin receptors. Vitamins and Hormones 63 195-232.

Scimonelli T, Celis ME \& Eberle AN 1987 Changes in alphamelanocyte-stimulating hormone content in discrete hypothalamic areas of the male rat during a twenty-four-hour period. Hormone Research 27 78-83.

Storch KF, Lipan O, Leykin I, Viswanathan N, Davis FC, Wong WH \& Weitz CJ 2002 Extensive and divergent circadian gene expression in liver and heart. Nature 417 78-83.

Wikberg JE, Muceniece R, Mandrika I, Prusis P, Lindblom J, Post C \& Skottner A 2000 New aspects on the melanocortins and their receptors. Pharmacological Research 42 393-420.

De Wildt DJ, Krugers H, Kasbergen CM, De Lang H \& Versteeg DH 1993 The hemodynamic effects of gamma 2-melanocyte-stimulating hormone and related melanotropins depend on the arousal potential of the rat. European Journal of Pharmacology 233 157-164.

De Wildt DJ, Van der Ven JC, Van Bergen P, De Lang H \& Versteeg DH 1994 A hypotensive and bradycardic action of gamma 2-melanocyte-stimulating hormone (gamma 2-MSH) microinjected into the nucleus tractus solitarii of the rat. Naunyn-Schmiedeberg's Archives of Pharmacology 349 50-56.

Young ME 2006 The circadian clock within the heart: potential influence on myocardial gene expression, metabolism, and function. American Journal of Physiology. Heart and Circulatory Physiology $290 \mathrm{H1}-\mathrm{H} 16$.

Young ME, Razeghi P, Cedars AM, Guthrie PH \& Taegtmeyer H $2001 a$ Intrinsic diurnal variations in cardiac metabolism and contractile function. Circulation Research 89 1199-1208.

Young ME, Razeghi P \& Taegtmeyer H $2001 b$ Clock genes in the heart: characterization and attenuation with hypertrophy. Circulation Research 88 1142-1150.

Received in final form 28 May 2008

Accepted 11 June 2008

Made available online as an Accepted Preprint 12 June 2008 